\title{
Protection of innate immunity by C5aR antagonist in septic mice
}

\author{
MARKUS S. HUBER-LANG, NIELS C. RIEDEMAN, J. VIDYA SARMA, ELLEN M. YOUNKIN, \\ STEPHANIE R. MCGUIRE, INES J. LAUDES, KRISTINA T. LU, REN-FENG GUO, \\ THOMAS A. NEFF, VAISHALEE A. PADGAONKAR, JOHN D. LAMBRIS, * L. SPRUCE,* \\ D. MASTELLOS, * FIRAS S. ZETOUNE, AND PETER A. WARD ${ }^{1}$ \\ Department of Pathology, University of Michigan Medical School, Ann Arbor, Michigan, USA; \\ and *Department of Pathology and Laboratory Medicine, University of Pennsylvania, \\ Philadelphia, Pennsylvania, USA
}

\begin{abstract}
Innate immune functions are known to be compromised during sepsis, often with lethal consequences. There is also evidence in rats that sepsis is associated with excessive complement activation and generation of the potent anaphylatoxin C5a. In the presence of a cyclic peptide antagonist (C5aRa) to the C5a receptor $(\mathrm{C5aR})$, the binding of murine ${ }^{125} \mathrm{I}-\mathrm{C} 5 \mathrm{a}$ to murine neutrophils was reduced, the in vitro chemotactic responses of mouse neutrophils to mouse C5a were markedly diminished, the acquired defect in hydrogen peroxide $\left(\mathrm{H}_{2} \mathrm{O}_{2}\right)$ production of $\mathrm{C} 5 \mathrm{a}$-exposed neutrophils was reversed, and the lung permeability index (extravascular leakage of albumin) in mice after intrapulmonary deposition of IgG immune complexes was markedly diminished. Mice that developed sepsis after cecal ligation/puncture (CLP) and were treated with C5aRa had greatly improved survival rates. These data suggest that C5aRa interferes with neutrophil responses to $\mathrm{C} 5 \mathrm{a}$, preventing $\mathrm{C} 5 \mathrm{a}$-induced compromise of innate immunity during sepsis, with greatly improved survival rates after CLP.-Huber-Lang, M. S., Riedeman, N. C., Sarma, J. V., Younkin, E. M., McGuire, S. R., Laudes, I. J., Lu, K. T., Guo, R.-F., Neff, T. A., Padgaonkar, V. A., Lambris, J. D., Spruce, L., Mastellos, D., Zetoune, F. S., Ward, P. A. Protection of innate immunity by $\mathrm{C} 5 \mathrm{aR}$ antagonist in septic mice. FASEB J. 16, 1567-1574 (2002)
\end{abstract}

Key Words: sepsis $\cdot$ neutrophil $\cdot$ oxidative burst $\cdot$ blood clearance

THE SYSTEMIC INFLAMMATORY response during sepsis is characterized by an excessive stimulation of inflammatory pathways (1) and impairment of innate immunity (2). Whereas the complement cascade (3-5) and the chemokine-cytokine networks $(6,7)$ are strongly activated during sepsis, innate immune function is severely compromised, as reflected by impairment of phagocytic cell function (phagocytosis, chemotaxis, and $\mathrm{H}_{2} \mathrm{O}_{2}$ production) during sepsis $(2,8-10)$. In humans with sepsis, harmful outcomes have been correlated with increased plasma levels of complement activation products C3a, C4a, and C5a $(9,11)$ together with impairment of the bactericidal activity of neutrophils $(8,12$,
13). The complement activation product C5a and receptor interactions with complement activation products (14) have been shown to play a pivotal role in development of the systemic inflammatory response during experimental sepsis (3) and in sepsis-induced multiorgan failure (MOF) $(4,15)$. After intraperitoneal (i.p.) injection of zymosan particles, which induce potent complement activation and MOF, C5-deficient $\left(\mathrm{C} 5^{-/-}\right)$mice exhibited increased survival rates (15). In a model of acute endotoxemia, $\mathrm{C} 5^{-/-}$mice showed improved hepatic and pulmonary function compared with their $\mathrm{C5}^{+/+}$littermates (16). In rats undergoing the cecal ligation/puncture (CLP), which closely mimics the pathophysiology of human sepsis $(17,18)$, we have recently shown that intravenous (i.v.) administration of antibodies to C5a has substantial protective effects. These were associated with preservation in blood neutrophils of C5a binding sites and retention of the oxidative burst, concomitant reduction in levels of bacteremia, and improved multi-organ function $(3,4,19)$.

The various effects of C5a have been the subject of many studies, particularly its interaction with the C5a receptor $(\mathrm{C5} \mathrm{aR})$, which is expressed on numerous myeloid (20-22) and nonmyeloid cells (23-25). In C5aRdeficient mice $\left(\mathrm{C}_{5} \mathrm{aR}^{-/-}\right)$, IgG immune complex (IC) -induced inflammatory responses in lungs, peritoneum, and skin were attenuated, associated with reduced neutrophil influx and reduced microvascular permeability changes (26), implying an important role for C5aR in the mechanisms of these inflammatory responses. In sepsis, blockade of C5aR by C5aRa was considered to be an intervention that might protect against excessive C5a production and related impairment of innate immunity. Using C5aRa, F[OPdChaWR] (Phe-[Orn-Pro-D-cyclohexylalanine-Trp-Arg]) $(27,28)$, we demonstrate that this inhibitor blocks binding of C5a to mouse neutrophils and the ability of these cells to respond chemotactically to recombinant mouse C5a. We show the ability of C5aRa to prevent loss of the respiratory burst in mouse neutrophils

\footnotetext{
${ }^{1}$ Correspondence: Department of Pathology, The University of Michigan Medical School, 1301 Catherine Road, Ann Arbor, MI 48109-0602, USA. E-mail:pward@umich.edu
} 
exposed to C5a. We also demonstrate the ability of C5aRa to reduce lung injury after IC deposition and to dramatically improve survival rates in CLP mice.

\section{MATERIALS AND METHODS}

\section{Reagents and chemicals}

All materials were obtained from Sigma Chemical Co. (St. Louis, MO) unless otherwise indicated.

\section{Cloning and expression of mC5a}

Total RNA was isolated from normal mouse liver tissue using the guanidine isothiocyanate method. The mC5a sequence was subcloned into pET 15b expression vector (Novagen, Madison, WI) using the primers 5'-GTG TCG CGA GTC AGC CAT ATG AAC CTG CAT CTC CTA-3' (sense, NdeI site underlined) and 5'-GTC ACA TCG CGA CAC GGA TCC TCA CCT TCC CAG TTG GAC-3' (antisense, BamHI site underlined). After expression of mouse C5a in BL21 (DE3) pLysS cells (Novagen, Madison, WI), the recombinant protein was purified over a $\mathrm{Ni}^{2+}$ column and used for subsequent experiments. As will be shown later, mC5a had biological (chemotactic) activity and demonstrated high-affinity binding to mouse neutrophils.

\section{Synthesis and purification of C5aRa F[OPdChaWR]}

Synthesis of the linear hexapeptide F[OPdChaWR] was done as described previously (29), followed by cyclization involving the side chain of ornithine and carboxyl-terminal arginine (27). The peptide was purified using preparative reversedphase HPLC. Eluted fractions were characterized by mass spectrometry (matrix-assisted laser desorption ionization). The efficacy of the cyclic hexapeptide F[OPdChaWR] was characterized in vivo and in vitro, as described below.

\section{Models of inflammation}

\section{Cecal ligation puncture-induced sepsis}

Male specific pathogen-free B10.D2/nSnJ mice (6 to $8 \mathrm{wk}$ of age weighing 25-30 g; Jackson Laboratories, Bar Harbor, ME) were used in all experiments. Mice were anesthetized with ketamine i.p. (20 mg/100 g body weight). A $1 \mathrm{~cm}$-long midline incision was made to expose the cecum and adjoining intestine. With a 4-0 silk suture, the cecum was tightly ligated below the ileocecal valve without causing bowel obstruction. The cecum was punctured through and through with a 21 gauge needle and gently squeezed to extrude luminal contents, ensuring patency of the two puncture holes. The abdominal incision was then closed with a 4-0 nylon suture and skin metallic clips (Ethicon, Somerville, $\mathrm{NY})$. Sham-operated animals underwent the same procedure except for ligation and puncture of the cecum. Immediately thereafter, CLP mice received either $200 \mu \mathrm{L}$ of saline alone or C5aRa in $200 \mu \mathrm{L}$ saline i.v. (at a final concentration of 1-3 $\mathrm{mg} / \mathrm{kg}$ body weight). In one experiment, i.v. infusion of C5aRa was delayed for $6 \mathrm{~h}$. Before and after surgery, mice had unrestricted access to food and water. Survival rates were determined over a 9 day period, with assessment every $6 \mathrm{~h}$.

IgG immune complex-induced lung injury

Male specific pathogen-free B10.D2/nSnJ mice were anesthetized i.p. with ketamine (20 mg/100 g body weight). To induce acute inflammatory lung injury, mice were intratra- cheally instilled with $250 \mu \mathrm{g}$ antibody to bovine serum albumin (anti-BSA; ICN Biomedicals, Costa Mesa, CA) in a volume of $40 \mu \mathrm{L}$ DPBS (Gibco BRL, Grand Island, NY), followed by i.v. injection of $500 \mu \mathrm{g}$ BSA ( $<1 \mathrm{ng}$ endotoxin/ $\mathrm{mg}$ ) in $200 \mu \mathrm{L}$ DPBS. Some animals received C5aRa (1 $\mathrm{mg} / \mathrm{kg}$ body weight) intratracheally together with the antiBSA. Negative control animals were subjected to intratracheal instillation of $40 \mu \mathrm{L}$ DPBS alone. For analysis of pulmonary vascular permeability, trace amounts of ${ }^{125}$ I-labeled BSA were injected i.v. Four h after IgG immune complex deposition, mice were killed, the pulmonary circulation flushed with 1 $\mathrm{mL}$ DPBS by pulmonary artery injection, and the lungs surgically removed. The extent of lung injury was quantified by calculating the lung permeability index, determined by comparing the amount of ${ }^{125}$ I-BSA present in lung parenchyma to the amount present in $100 \mu \mathrm{L}$ blood obtained from the inferior vena cava at the time of death.

\section{Isolation of mouse peritoneal neutrophils}

Mice were injected i.p. with $2.5 \mathrm{~mL}$ sterile $3 \%$ thioglycolate medium (DIFCO Laboratories, Detroit, MI) for harvesting of mouse neutrophils (30). Five hours later, mice were killed and the peritoneal cavity was lavaged four times with $10 \mathrm{~mL}$ DPBS. Fluids were centrifuged and residual red blood cells removed by a hypotonic lysis step. Remaining peritoneal cells were washed and resuspended in HBSS. Aliquots of cells were stained with Diff-Quik Stain (Dade International, Miami, FL) and examined for neutrophil purity $(>95 \%)$ and viability $(>97 \%)$ by trypan blue exclusion (31).

\section{Radiolabeling and binding assays}

For binding studies, mC5a was labeled with ${ }^{125}$ I using the chloramine T-based protocol (32) with gentle oxidation, which preserves chemotactic activity of mC5a for mouse neutrophils (data not shown). Isolated neutrophils were incubated for $1 \mathrm{~h}$ at $4^{\circ} \mathrm{C}$ in binding buffer (HBSS without $\mathrm{Ca}^{2+}$ and containing $1 \%$ BSA) to block nonspecific surface binding sites. After gentle washing, neutrophils $\left(2 \times 10^{6}\right.$ cells) were incubated at $4^{\circ} \mathrm{C}$ in binding buffer (HBSS with $\mathrm{Ca}^{2+}$ containing $0.1 \%$ BSA) (in a final volume of $200 \mu \mathrm{L}$ ) with 100 pM ${ }^{125} \mathrm{I}-\mathrm{mC5}$ a (specific activity $23.5 \mu \mathrm{Ci} / \mu \mathrm{g}$ ) in the absence or presence of increasing amounts of either unlabeled mC5a or C5aRa (ranging from $10^{-12}$ to $10^{-4} \mathrm{M}$ ). After an incubation interval of $20 \mathrm{~min}$ at $4^{\circ} \mathrm{C}$, cell suspensions were layered over $20 \%$ sucrose and sedimented by centrifugation at 11,000 $g$ (Beckman Microfuge B, Palo Alto, CA) for $2 \mathrm{~min}$. The tubes were then frozen at $-80^{\circ} \mathrm{C}$ and the tips containing the cell pellet were cut off to determine the cell-bound ${ }^{125} \mathrm{I}-\mathrm{mC5} \mathrm{a}$, using a gamma counter (1261 Multigamma, EG \& G Wallac, Co., Gaithersburg, MD). Binding affinities ( $K_{d}$ values) of C5a were calculated in the conventional manner (22).

In another set of experiments, C5aRa was labeled with ${ }^{125} \mathrm{I}$ by the chloramine $\mathrm{T}$ method, taking advantage of the electrophilic aromatic region of phenylalanine (33). The integrity of ${ }^{125}$ I-C5aRa after the labeling procedure was confirmed in vitro by chemotaxis assays (see below). Using peritoneal mouse neutrophils, competitive binding studies using $100 \mathrm{pM}$

${ }^{125} \mathrm{I}-\mathrm{C} 5 \mathrm{aRa}$ (specific activity $33.9 \mu \mathrm{Ci} / \mu \mathrm{g}$ ) with increasing amounts of unlabeled C5aRa or mC5a were performed as described above.

\section{Chemotaxis assay}

After neutrophil isolation, cells were fluorescein-labeled with BCECF (2',7'-bis [2-carboxyethyl]-5-[and 6]-carboxy-fluorescein acetoxymethyl ester) (Molecular Probes, Eugene, OR). 
Labeled neutrophils $\left(5 \times 10^{6}\right.$ cells $\left./ \mathrm{mL}\right)$ were then loaded into the upper chambers of 96-well minichambers (NeuroProbe, Cabin John, MD). Lower chambers were loaded with increasing amounts of mC5a in the presence or absence of different concentrations of C5aRa, ranging from $0.1 \mathrm{nM}-10 \mu \mathrm{M}$. The upper and lower chambers were separated by a polycarbonate membrane of $3 \mu \mathrm{m}$ porosity. Minichambers were incubated for $60 \mathrm{~min}$ at $37^{\circ} \mathrm{C}$. The number of cells migrating through polycarbonate filters to the lower surface was measured by cytofluorometry (Cytofluor II, PerSeptive Biosystems, Framingham, MA). For each measurement, quadruplicate samples were used.

\section{Measurement of neutrophil oxidative burst}

$\mathrm{H}_{2} \mathrm{O}_{2}$ generation was determined in the presence of $1 \mathrm{mM}$ sodium azide. As indicated, mouse neutrophils $\left(2 \times 10^{6}\right.$ cells/ $\mathrm{mL})$ were pretreated with $\mathrm{mC5a}(10 \mathrm{nM})$ for $60 \mathrm{~min}$ at $37^{\circ} \mathrm{C}$ in the presence or absence of different amounts of C5aRa. To stimulate neutrophils, cells were then incubated with PMA (25 $\mathrm{ng} / \mathrm{mL})$ for an additional $10 \mathrm{~min}$. The reaction was stopped by addition of $0.1 \mathrm{~mL}$ trichloroacetic acid $(50 \% \mathrm{v} / \mathrm{v})$, then ferrous ammonium sulfate $(1.5 \mathrm{mM})$ and potassium thiocyanate $(0.25 \mathrm{M})$ were added to supernatant fluids. The absorbance of the ferrithiocyanate complex was measured at $480 \mathrm{~nm}$ and compared with a standard curve generated from dilutions of reference solutions of $\mathrm{H}_{2} \mathrm{O}_{2}$.

\section{Clearance studies}

To evaluate the blood clearance of $\mathrm{C} 5 \mathrm{aRa}$, anesthetized mice were injected i.v. with C5aRa ( $1 \mathrm{mg} / \mathrm{kg}$ body weight) in 200 $\mu \mathrm{L}$ DPBS containing trace amounts of ${ }^{125}$ I-C5aRa (specific activity $33.9 \mu \mathrm{Ci} / \mu \mathrm{g})$. Sixty seconds after administration, $5 \mu \mathrm{L}$ blood was drawn from a small incision at the tail tip, followed by direct pressure to stop further bleeding. Animals were killed after specified periods $(1,2,3,6,12,24,36,48,72$, $96 \mathrm{~h})$ and the radioactivity of blood samples $(100 \mu \mathrm{L}$ aliquots $)$ was measured in a gamma counter (1261 Multigamma, EG\&G, Wallac, Gaithersburg, MD) and compared with the value obtained $1.0 \mathrm{~min}$ after infusion of C5aRa.

\section{Statistical analyses}

All values were expressed as mean \pm SE. Results were considered statistically significant where $P<0.05$. For analysis of survival curves, $\log$ rank and $-2 \log$ rank tests were used. Outcomes in different treatment groups were compared using $\chi^{2}$ and Fisher's exact tests. Data sets of binding, chemotaxis and oxidative burst assays were analyzed with one-way ANOVA; differences in the mean values among experimental groups were then compared using the Tukey multiple comparison test.

\section{RESULTS}

\section{Ability of C5aRa to reduce binding of mC5a to mouse peritoneal neutrophils}

Recent reports have described C5aRa binding affinities to rat and human neutrophils $(28,34)$. To assess whether C5aRa also binds to mouse neutrophils, competitive binding studies using C5aRa and mC5a were undertaken. Mouse neutrophils (isolated from peritoneal exudates) were incubated for $20 \mathrm{~min}$ at $4^{\circ} \mathrm{C}$ with
$100 \mathrm{pM}^{125} \mathrm{I}-\mathrm{mC5}$ a in the presence of increasing doses of either unlabeled mC5a or C5aRa. As shown in Fig. 1 (filled circles), mC5a demonstrated dose-dependent competitive binding, with a calculated $K_{d}$ of $\sim 3 \mathrm{nM}$. C5aRa (open circles) also demonstrated significant competitive binding with a calculated $K_{d}$ of $\sim 30 \mathrm{nM}$. These experiments indicate that C5aRa inhibits the binding of mC5a to mouse neutrophils.

\section{Blocking by C5aRa of mouse neutrophil chemotactic responses to $\mathrm{mC5a}$}

To assess in vitro the effects of C5aRa on migrational responses of mouse neutrophils to mC5a, chemotactic responses in the absence or presence of a dose range of C5aRa were determined. When mouse neutrophils were exposed to mC5a (0.01-1000 nM), a typical dosedependent chemotactic response was found, reaching a plateau between 1 and $10 \mathrm{nM}$ mC5a (Fig. 2A, filled circles). In the presence of $1000 \mathrm{nM}$ C5aRa, the chemotactic response of mouse neutrophils was almost completely suppressed over a wide dose range (0.01$100 \mathrm{nM}$ ) of mC5a.

In a second set of experiments, the chemotactic responses of mouse neutrophils to a constant dose (10 $\mathrm{nM}$ ) of mC5a in the presence of increasing C5aRa concentrations $(0.1 \mathrm{nM}-10 \mu \mathrm{M})$ were assessed (Fig. $2 B)$. The presence of $10 \mathrm{nM} \mathrm{C5aRa}$ alone evoked a very weak chemotactic response, if at all (gray bar). As expected, $10 \mathrm{nM}$ mC5a in the absence of C5aRa evoked a robust chemotactic response of neutrophils (first black bar). In contrast, a dose-dependent inhibition of neutrophil response to mC5a was observed in the copresence of $0.1-10^{4} \mathrm{nM}$ C5aRa. In this assay the calculated IC50 for C5aRa was $\sim 0.5 \mathrm{nM}$. These data indicate a dose-dependent inhibition by C5aRa of chemotactic responses by mouse neutrophils to mC5a.

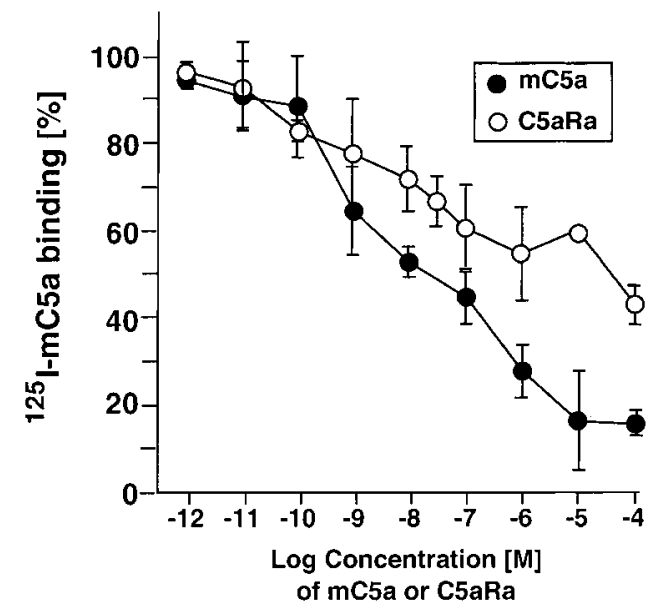

Figure 1. Inhibition of ${ }^{125}$ I-recombinant mouse (m) C5a binding to mouse neutrophils in the presence of increasing concentrations of unlabeled mC5a or C5aRa. Data are expressed as a percent of binding values using $100 \mathrm{pM}{ }^{125} \mathrm{I}-$ mC5a. 

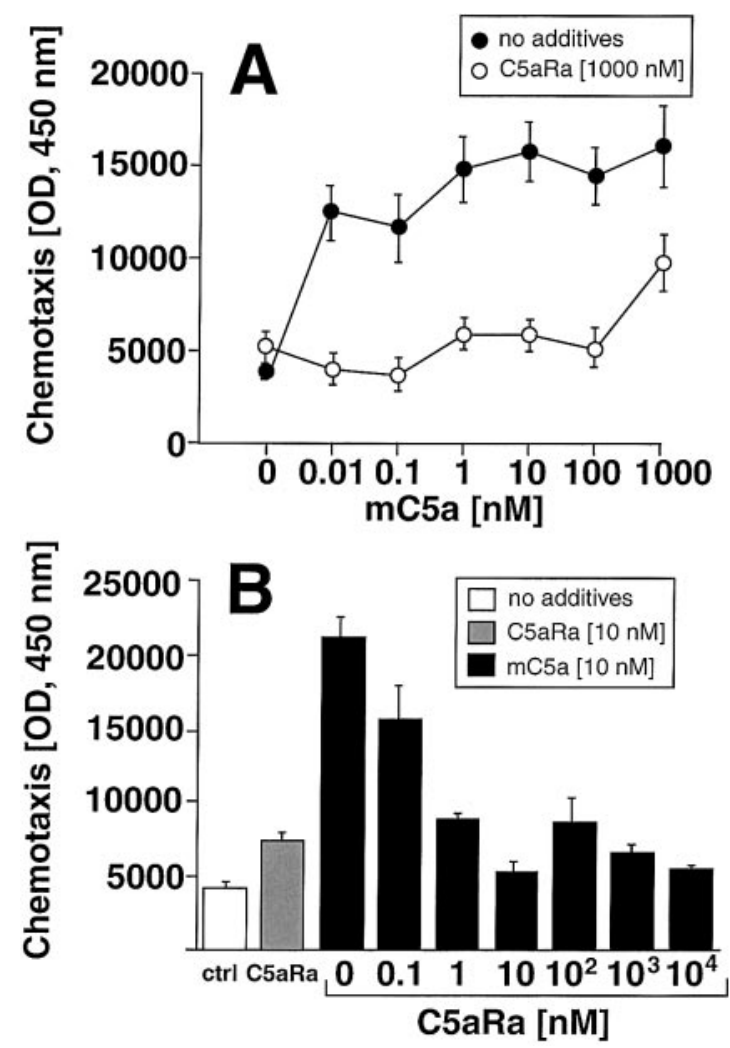

Figure 2. Inhibitory effects of C5aRa on chemotactic responses of mouse neutrophils to recombinant mouse C5a. A) Chemotactic responses of mouse neutrophils to a range of concentrations of recombinant mouse C5a in the absence (filled circles) or presence of $1.0 \mu \mathrm{M} \mathrm{C5aRa} \mathrm{(open} \mathrm{circles).} \mathrm{B)}$ Blockade of chemotactic activity (using $10 \mathrm{nM} \mathrm{mC5a)} \mathrm{of}$ mouse neutrophils in the presence of a range of concentrations of C5aRa.

\section{Reversal by C5aRa of C5a-induced defect in the oxidative burst of neutrophils}

During sepsis, plasma levels of C5a are increased $(9,11)$ and suppression of the neutrophil oxidative burst (production of $\mathrm{O}_{2} \bigcirc$ and $\mathrm{H}_{2} \mathrm{O}_{2}$ ) occurs, resulting in impaired bacterial killing $(3,13)$. In CLP-induced sepsis in rats, we have recently shown that the $\mathrm{H}_{2} \mathrm{O}_{2}$ response of blood neutrophils is defective (3). In vitro exposure of neutrophils to C5a reproduces the defect in the oxidative response found in blood neutrophils during sepsis (3). In the current study, we evaluated the effects of C5aRa on the C5a-induced loss of the oxidative response in neutrophils. Mouse neutrophils were exposed to buffer (ctrl), to $10 \mathrm{nM}$ mC5a alone, or to 10 $\mathrm{nM}$ C5aRa alone for $60 \mathrm{~min}$ at $37^{\circ} \mathrm{C}$, followed by addition (where indicated) of PMA $(25 \mathrm{ng} / \mathrm{mL}$ for 10 $\min$ at $37^{\circ} \mathrm{C}$ ). The $\mathrm{H}_{2} \mathrm{O}_{2}$ response was then measured. As shown in Fig. 3, neither mC5a alone nor C5aRa alone significantly altered basal $\mathrm{H}_{2} \mathrm{O}_{2}$ production in neutrophils when compared with ctrl cells (white bar and first two light gray bars). Addition of PMA to neutrophils otherwise untreated caused the expected robust increase in $\mathrm{H}_{2} \mathrm{O}_{2}$ generation (black bar). In mC5a-exposed neutrophils (in the absence of C5aRa), followed by stimulation with PMA, production of $\mathrm{H}_{2} \mathrm{O}_{2}$ was completely abolished (first cross-hatched bar). The copresence of $10 \mathrm{nM}$ mC5a with increasing concentrations of C5aRa $(10 \mathrm{nM}-10 \mu \mathrm{M})$ with neutrophils for 60 min at $37^{\circ} \mathrm{C}$ led to a progressive and significant restoration of $\mathrm{H}_{2} \mathrm{O}_{2}$ generation (second to fifth crosshatched bars). Thus, C5a-induced impairment of the oxidative response in activated neutrophils could be reversed by the presence of $\mathrm{C} 5 \mathrm{aRa}$ in a dose-dependent manner. These data parallel the efficacy of $\mathrm{C} 5 \mathrm{aRa}$ in blockade of C5a-dependent neutrophil chemotactic activity (Fig. 2B).

\section{C5aRa clearance in mouse blood}

To determine whether treatment of CLP mice with C5aRa would improve survival rates, we first assessed the in vivo blood clearance of C5aRa. C5aRa was ${ }^{125}$ I-labeled before i.v. administration into mice. To ensure the functional integrity of C5aRa after the labeling procedure, chemotaxis assays were performed using ${ }^{125} \mathrm{I}-\mathrm{C} 5 \mathrm{aRa}(10 \mathrm{nM})$ in the presence of mC5a (1-100 nM). Mouse neutrophils were exposed to a range of concentrations of mC5a in the absence or presence of $10 \mathrm{nM}^{125} \mathrm{I}-\mathrm{C} 5 \mathrm{aRa}$, similar to the protocol in Fig. 2B. As shown in Fig. 4 (inset), radiolabeled C5aRa virtually completely suppressed the chemotactic response to all doses of mC5a (open circles), indicating intact biological activity of ${ }^{125} \mathrm{I}$-C5 $5 \mathrm{aRa}$. The blood clearance of C5aRa in mice after a single i.v. bolus of 1 $\mathrm{mg} / \mathrm{kg}$ C5aRa with trace amounts of ${ }^{125}$ I-labeled C5aRa was determined. As shown in Fig. 4, a multiphasic decline in whole blood concentrations was observed. The early, rapid clearance phase $(\leq 3 \mathrm{~h})$ was characterized by a mean half-life of $\sim 4 \mathrm{~h}$, whereas the later phase (24-72 h) demonstrated a mean half-life of $\sim 12 \mathrm{~h}$. The slower clearance phase accounted for an average of $63 \%$ of the total area for the blood concentration vs.

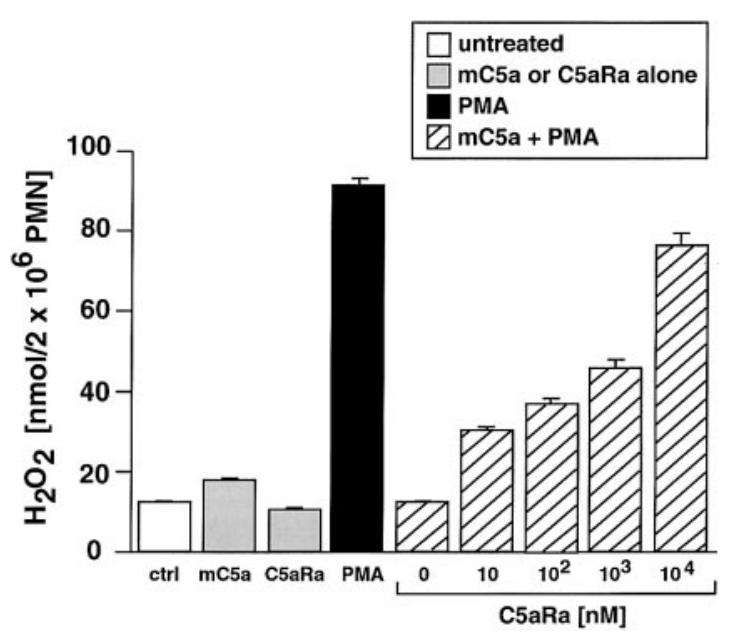

Figure 3. In vitro effects of $\mathrm{C} 5 \mathrm{aRa}$ on reversal of C5a-induced defective $\mathrm{H}_{2} \mathrm{O}_{2}$ responses of mouse neutrophils stimulated with PMA $(25 \mathrm{ng} / \mathrm{mL})$. Neutrophils were preincubated with $10 \mathrm{nM} \mathrm{mC5a}$ for $1 \mathrm{~h}$ at $37^{\circ} \mathrm{C}$ in the presence or absence of C5aRa, then stimulated with PMA. 


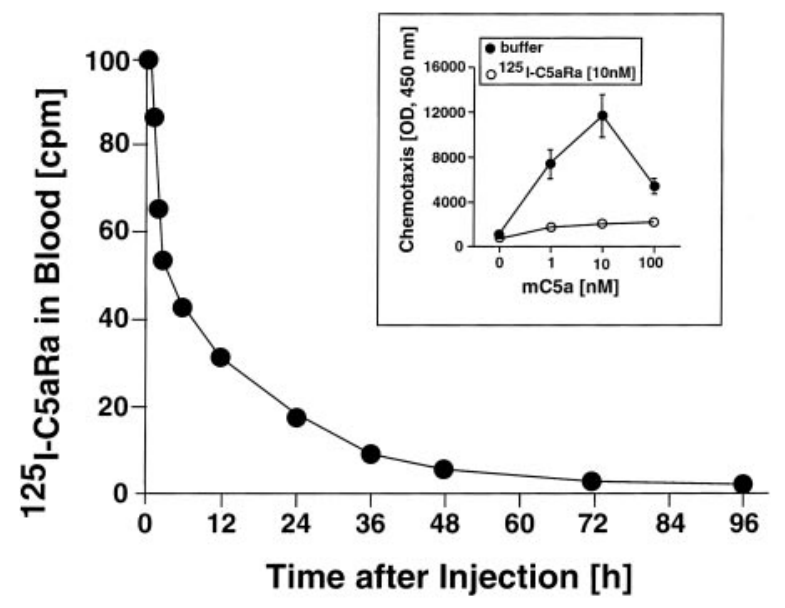

Figure 4. Blood clearance of ${ }^{125} \mathrm{I}-\mathrm{C} 5 \mathrm{aRa}$ in mice. After ${ }^{125} \mathrm{I}-$ labeling of $\mathrm{C} 5 \mathrm{aRa}$, its functional activity was determined in chemotaxis assays using increasing amounts of mC5a in the presence of $10 \mathrm{nM}{ }^{125} \mathrm{I}-\mathrm{C} 5 \mathrm{aRa}$ (inset). Semilogarithmic plots of blood clearance curve of ${ }^{125}$ I-C5aRa were normalized to the $1.0 \mathrm{~min}$ time point. Data are expressed as percent of blood values obtained immediately after i.v. injection of ${ }^{125}$ I-C5aRa. Mean \pm SE of 5 animals at each time point.

time; $36 \mathrm{~h}$ after C5aRa application, the C5aRa concentration reached $10 \%$ of the initial dose in blood.

\section{Ability of C5aRa to diminish C5a-dependent inflammatory lung injury in mice}

Lung inflammatory injury induced by intrapulmonary deposition of IgG immune complex is C5 and C5a dependent $(35,36)$. In the case of C5a, the bulk of C5a generated appears to be within the distal airway compartment (36). In preliminary experiments, we determined that the intratracheal instillation of $250 \mu \mathrm{g}$ anti-BSA with an i.v. infusion of $500 \mu \mathrm{g}$ BSA would induce acute inflammatory injury in mouse lung at $4 \mathrm{~h}$ (data not shown). Accordingly, these conditions were used in the mouse model of acute lung injury. To determine lung vascular leakage $4 \mathrm{~h}$ after immune complex deposition, extravasation of i.v. administered ${ }^{125}$ I-labeled BSA into lungs was measured. Control (ctrl) mice, which received $40 \mu \mathrm{L}$ sterile saline intratracheally, exhibited a vascular permeability index of $0.13 \pm 0.02$ (Fig. 5). This index rose nearly ninefold in mice with immune complex-induced alveolitis. However, the presence of C5aRa $(1 \mathrm{mg} / \mathrm{kg}$ body weight given intratracheally at time 0 ) resulted in a substantial reduction in the permeability index (immune complex $\pm \mathrm{C} 5 \mathrm{aRa}$ ) vs. the positive control group of immune complexes alone. The C5aRa-treated group showed a significant reduction $(\sim 70 \%, P<0.05)$ in the permeability index. Higher doses of C5aRa (up to 10 $\mathrm{mg} / \mathrm{kg}$ ) did not further reduce the permeability index (data not shown). Thus, in animals receiving a direct intrapulmonary insult after deposition of $\mathrm{IgG}$ immune complexes, airway presence of C5aRa caused significantly reduced lung vascular leakage.

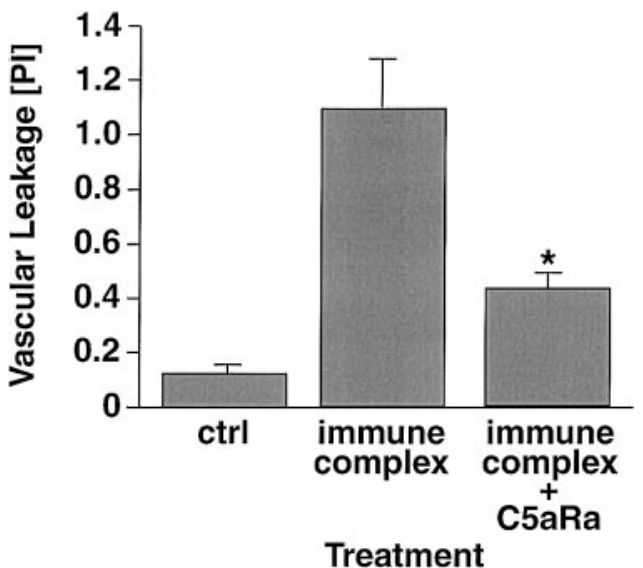

Figure 5. Effects of C5aRa $(1 \mathrm{mg} / \mathrm{kg}$ body weight administered intratracheally) on acute inflammatory injury of mouse lungs after intrapulmonary deposition of IgG immune complexes. The lung vascular permeability index was assessed by measuring extravasation of i.v. administered ${ }^{125}$ I-BSA $4 \mathrm{~h}$ after initiation of the reactions. Negative control group (ctrl); intrapulmonary deposition of IgG immune complexes (IC) in the absence or presence of $1 \mathrm{mg} / \mathrm{kg}$ body weight C5aRa $(\mathrm{IC}+\mathrm{C} 5 \mathrm{aRa})$. For each group, $n=6$.

\section{Protective effects of C5aRa in CLP-induced sepsis}

Mice with CLP-induced sepsis received i.v. either 200 $\mu \mathrm{L}$ sterile saline immediately after the CLP procedure or C5aRa $(1.0-3.0 \mathrm{mg} / \mathrm{kg}$ body weight) in $200 \mu \mathrm{L}$ sterile saline. Survival of mice was assessed over a 9 day period. In one group, the infusion of C5aRa was delayed until $6 \mathrm{~h}$ after CLP. The data are shown in Fig. 6. In the sham-operated group, which underwent the same surgical procedure without CLP, all animals survived the 9 day interval $(n=10)$ (data not shown). Mice subjected to CLP in the absence of a protective intervention (saline) developed typical clinical signs of sepsis 12-24 h after CLP: decreased physical activity, lethargy, loss of congregation for group warmth, dehy-

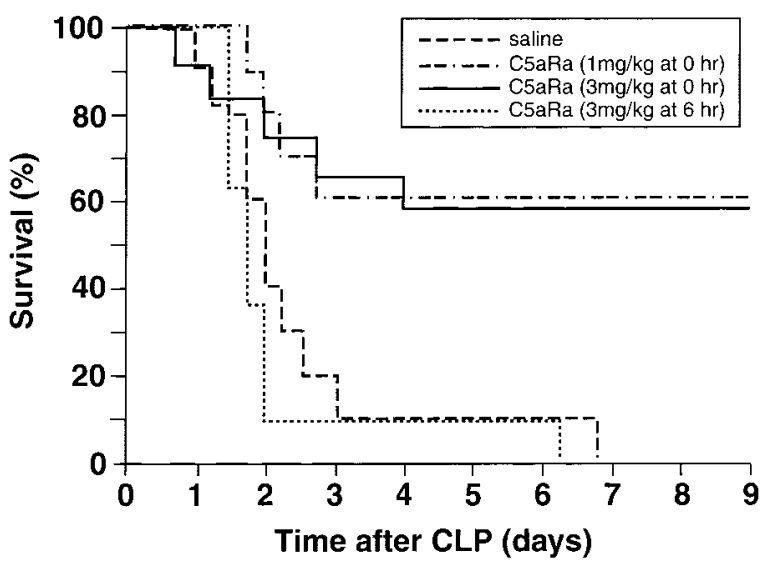

Figure 6. Survival curves of mice after CLP as a function of i.v. treatment with either $200 \mu \mathrm{L}$ saline alone or C5aRa (1-3 $\mathrm{mg} / \mathrm{kg}$ body weight) in $200 \mu \mathrm{L}$ saline. Also indicated is a group treated with C5aRa (3 mg/ $\mathrm{kg}$ body weight) $6 \mathrm{~h}$ after CLP. For each group, $n=10$. 
dration, piloerection, glazed eyes with crusting exudates, diarrhea, and dark urine. The survival rate by the third day in this group was only $10 \%$ but $60 \%$ in the C5aRa-treated group ( $1 \mathrm{mg} / \mathrm{kg}$ at time 0$)$ survived. By day 7 there were no survivors in the CLP group not receiving protective intervention, whereas in the C5aRa-treated group (1-3 mg C5aRa/ $\mathrm{kg}$ at time 0 ) at day 4 and beyond survival remained constant at $60 \%$. By the fifth day in the CLP group treated with C5aRa, there were no clinical signs of sepsis. Differences between the 9 day outcomes of CLP animals that did not receive C5aRa and those that received C5aRa ( 1 or 3 $\mathrm{mg} / \mathrm{kg})$ were statistically significant $(P<0.03$ for the C5aRa-treated CLP group vs. CLP unprotected group and $P<0.05$ for the C5aRa-treated CLP groups vs. sham operated group, respectively), indicating significantly improved survival rates by administration of C5aRa. The survival pattern in CLP mice receiving $3.0 \mathrm{mg} / \mathrm{kg}$ body weight was the same as those receiving $1.0 \mathrm{mg}$ $\mathrm{C} 5 \mathrm{aRa} / \mathrm{kg}$ body weight. When C5aRa $(3 \mathrm{mg} / \mathrm{kg}$ body weight) was given $6 \mathrm{~h}$ after CLP, the protective effects were lost (Fig. 6), suggesting that interception of C5a by C5aRa in this model must occur in the first few hours of sepsis for clinical benefit.

\section{DISCUSSION}

The innate immune response provides the body with host defenses that represent the first line of protection against bacterial infections (37). During the systemic inflammatory response in sepsis, the protective functions of neutrophils are significantly compromised, seriously impairing the clearance of bacteria from blood $(3,13)$, with resultant organ damage $(2,4,9)$ and a high incidence of lethality $(2,11)$. In experimental sepsis induced by CLP, C. $3^{-/-}$or $\mathrm{C}^{-/-}$mice were more sensitive to the lethal effects of CLP compared with wild-type controls, suggesting that complement is essential for the full expression of innate immunity during polymicrobial sepsis (38). Recent studies with complement receptor 2-deficient $\left(\mathrm{CR}^{-/-}\right)$(39) or

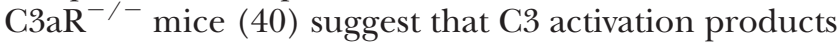
are required for survival after infusion of lipopolysaccharide (LPS). In contrast, the absence of C5 (C5 ${ }^{-/-}$ mutant mice) appears to confer some protective effects in sepsis (15). It has been shown that administration of C5aRa (F[OPdChaWR]) can antagonize LPS-induced neutropenia in rats $(29,41)$. Almost a decade ago, the hexapeptide MeFKPdChaFR was synthesized by multiple substitutions with unnatural amino acids in the carboxyl-terminal peptide region of the C5a molecule. This peptide was shown to exhibit limited antagonistic effects on C5a-exposed human neutrophils $(42,43)$. Increasing the aromaticity of the fifth residue of the hexapeptide led to an increased C5aR antagonism, which was reported to be the first full C5aR antagonist (44). In an attempt to increase the stability and improve target selectivity of the molecule, replacement of lysine by ornithine and cyclization of the molecule was carried out, resulting in F[OpdChaWR $]$ (28). This small C5aRa molecule antagonized the binding of human C5a to human and rat neutrophils $(28,34)$. In the present study, the same C5aRa demonstrated competitive binding for recombinant mouse C5a to mouse neutrophils (Fig. 2). The incomplete albeit significant antagonism in binding and the $K_{d}$ value for C5aRa, which are dependent on the species from which the neutrophils are isolated (human, rat or mouse), might be explained by structural diversity between C5aR of different species, as shown by $\sim 70 \%$ nonhomogeneity of the extracellular domains of human and mouse $\mathrm{C} 5 \mathrm{aR}$ (45). To determine whether C5aRa antagonizes the acute inflammatory response, mice were subjected to immune complex-induced lung injury. The severity of lung injury as assessed by the pulmonary permeability index (Fig. 5) was substantially reduced in the presence of C5aRa. C5aRa was given intratracheally based on previous observations that the immune complex-induced lung injury appears to be triggered mainly by locally generated C5a together with cytokines/chemokines within the lung $(36,46)$. In rats, intratracheal instillation of anti-C5a antibodies (which neutralize C5a) led to similar results in a similar model of lung injury (36). Supporting these findings and using the same model of lung injury, $\mathrm{C} 5^{-/-}$mice have been reported to exhibit a less severe inflammatory response than their C5 sufficient littermates (35). To evaluate the effects of C5aRa on systemic inflammatory responses, the presence of C5aRa inhibited complement-induced neutropenia and LPS-induced mortality in rats $(34,41)$. Administration of a single dose of C5aRa (at a weight-related concentration effective in other species) $(34,41)$ immediately after induction of CLP in mice resulted in great improvement of longterm survival, indicating protective effects of C5aRa during sepsis (Fig. 6). In rats with CLP, in vivo interception of C5a with polyclonal antibody to a peptide from the midregion of C5a reduced lethality $(3,19)$, indicating overall protective effects by blockade of the interaction between C5a and C5aRa. Companion experiments cannot be done in mice because of the lack of blocking antibodies to mouse C5a.

During CLP-induced sepsis, excessive production of C5a can lead to a global neutrophil dysfunction as defined by loss of C5a binding on C5aR $(4,8,9)$, alteration of the chemotactic responsiveness $(4,8,9)$, a defective oxidative burst $(3,10,19)$, and impaired bacterial killing $(3,13)$. In an attempt to simulate in vitro pathophysiological conditions present during sepsis with reported plasma levels of C5a of $>100 \mathrm{ng} / \mathrm{mL}$ serum (8), mouse neutrophils were exposed to increasing amounts of mouse C5a. As expected, a typical chemotactic response curve of mouse neutrophils to mouse C5a was observed, but in the copresence of C5aRa an almost complete dose-dependent inhibition of the chemotactic response was seen (Fig. 2). With its capacity for bacterial killing, the neutrophil is known to be a cornerstone of innate immunity, but neutrophils also have an implicit capacity for host tissue destruction 
(12) that may contribute to sepsis-induced organ dysfunction/failure. Therefore, it is possible that C5aRa blockade of C5a may diminish excessive recruitment of neutrophils and the attendant release of toxic reactive oxygen species, proteinases, defensins, etc. (12), leading to protection of tissues and organs. After recruitment and hyperactivation (hyperresponsive phase of sepsis), neutrophils have been reported to progress to a hyporesponsive phase $(10,47)$ with loss of multiple functions including the respiratory burst $(3,4,19)$ and associated bacterial killing (3). Therefore, we exposed neutrophils to amounts of C5a appearing during sepsis (8) in the presence or absence of C5aRa. Preexposure of $10 \mathrm{nM} \mathrm{mC5a}$ led to a loss of respiratory burst in PMA-stimulated neutrophils (ref 19 and Fig. 3). However, in the presence of $\mathrm{C} 5 \mathrm{aRa}$, the respiratory burst of neutrophils (generation of $\mathrm{O}_{2}^{*}$ and $\mathrm{H}_{2} \mathrm{O}_{2}$ ) was preserved in proportion to the concentration of C5aRa (Fig. 3), which may explain why C5aRa is protective in the CLP model of sepsis.

Other molecules with C5aR antagonistic activity have been described (48-50). Derived from a human C5a phage display library in which the carboxyl terminus of C5a was mutated, these compounds have revealed some C5a antagonistic effects and have been shown to induce some protection in different animal models of immune complex injury. These compounds have also decreased tissue injury in a model of ischemia and reperfusion (51). By modification of the carboxyl terminus of C5a, others found a monomer (C5aRam) and its dimer (C5aRad) to exhibit potent C5aR antagonistic activity (52). The latter antagonist reduced infarct size and attenuated the inflammatory response in a porcine model of cardiac ischemia/reperfusion injury (53). Furthermore, a ribosomal protein (S19) has recently been reported to exhibit (after activation by coagulation factor XIIIa) molecular mimicry for C5a, inhibiting C5a-induced chemotactic responses of leukocytes (54). Most of these molecules with C5aR antagonistic activity are large and complex molecules with inconstant structures or feature linear peptides that would likely be rapidly metabolized, have large antigenic surfaces, and demonstrate unfavorable metabolic profiles (41). Although the small acyclic peptide MeFKPdChaFR has been described to be relatively resistant to protease attack in vitro (41), additional cyclization of the molecule was performed to achieve increased resistance against proteolytic cleavage and to restrict its structural freedom (41). In vivo clearance of C5aRa in mice has not been reported. In the present study, we labeled the C5aRa with ${ }^{125}$ I without compromising the molecule's biological function as determined by chemotaxis assays (Fig. 4). Clearance studies were done to determine blood clearance of C5aRa over time. After administration of ${ }^{125} \mathrm{I}-\mathrm{C} 5 \mathrm{aRa}$, an initial rapid distribution phase (over the first $3 \mathrm{~h}$ ) was found, most likely due to vascular equilibration (19) and binding to circulating neutrophils, followed by a slower phase of clearance with a prolonged half-life of C5aRa. The relatively slow clearance of C5aRa (at $12 \mathrm{~h}$ and 20-25\% of the initially applied dose after $12 \mathrm{~h}$ ) was unexpected. Similar results with protective effects of anti-C5a antibodies when administered within the first $12 \mathrm{~h}$ after onset of sepsis have been published recently in rats (19). The present data suggest that interventions designed to antagonize development of defects of innate immunity during sepsis in rodents caused by production of C5a may have application to humans with sepsis. [F

We thank Beverly Schumann and Peggy Otto for excellent secretarial assistance in the preparation of the manuscript. We also thank Ms. F. A. Bjork and Dr. D. McConnell for ${ }^{125}$ I-labeling C5aRa. Grant support included National Institutes of Health GM 61656 (to P.W.) and GM 29507 (to P.W.).

\section{REFERENCES}

1. Glauser, M. P. (2000) Pathophysiologic basis of sepsis: considerations for future strategies of intervention. Crit. Care Med. 28, 4-8

2. Faist, E., Schinkel, C., and Zimmer, S. (1996) Update on the mechanisms of immune suppression of injury and immune modulation. World J. Surg. 20, 454-459

3. Czermak, B. J., Sarma, V., Pierson, C. L., Warner, R. L., Huber-Lang, M., Bless, N. M., Schmal, H., Friedl, H. P., and Ward, P. A. (1999) Protective effects of C5a blockade in sepsis. Nature Med.. 5, 788-792

4. Huber-Lang, M., Sarma, V. J., Lu, K. T., McGuire, S. R., Padgaonkar, B. A., Guo, R. F., Younkin, E. M., Kunkel, R. G., Ding, J., Erickson, R., Curnutte, J. T., and Ward, P. A. (2001) Role of C5a in multi-organ failure. J. Immunol. 166, 1193-1199

5. Utoh, J., Utsunomiya, T., Imamura, T., Katsuya, H., Miyauchi, Y., Kambara, T. (1989) Complement activation and neutrophil dysfunction in burned patients with sepsis. Jpn. J. Surg. 19, 462-467

6. Williams, M. A., Cave, C. M., Quaid, G., and Solomkin, J. S (1999) Chemokine regulation of neutrophil function in surgical inflammation. Arch. Surg. 134, 1360-1366

7. Matasukawa, A., Kaplan, M. H., Hogaboam, C. M., Lukacs, N. W., and Kunkel, S. L. (2001) Pivotal role of signal transducer and activator of transcription (stat) 4 and stat 6 in the innate immune response during sepsis. J. Exp. Med. 193, 679-688

8. Solomkin, J. S., Jenkins, M. K., Nelson, R. D., Chenoweth, D., and Simmons, R. L. (1981) Neutrophil dysfunction in sepsis. II. Evidence for the role of complement activation products in cellular deactivation. Surgery 90, 319-327

9. Goya, T., Morisaki, T., and Motomichi. T. (1994) Immunologic assessment of host defense impairment in patients with septic multiple organ failure: relationship between complement activation and changes in neutrophil function. Surgery 115, 145-155

10. Zimmerman, J. J., Shelhamer, J. H., and Parrillo, J. (1985) Quantitative analysis of polymorphonuclear leukocyte superoxide anion generation in critically ill children. Crit. Care Med. 13, 143-150

11. Hecke, F., Schmidt, U., Kola, A., Bautsch, W., Klos, A., and Kohl, J. (1997) Circulating complement proteins in multiple trauma patients-correlation with injury severity, development of sepsis, and outcome. Crit. Care Med. 25, 2015-2024

12. Burg, N. D., and Phillinger, M. H. (2001) The neutrophil: function and regulation in innate and humoral immunity. Clin. Immunol. 99, 7-17

13. Koch, T., Annus, C., Schiefer, H. G., van Ackern, K., and Neuhof, H. (1997) Impaired bacterial clearance after activation of the complement and coagulation systems. Shock 7, 42-48

14. Ember, J. A., and Hugli, T. E. (1997) Complement factors and their receptors. Immunopharmacology 378, 3-15

15. Miller, C. G., Cook, D. N., and Kotwal, G. J. (1996) Two chemotactic factors, C5a and MIP-1alpha, dramatically alter the mortality from zymosan-induced multiple organ dysfunction syndrome (MODS): C5a contributes to MODS while MIP-1alpha has a protective role. Mol. Immunol. 33, 1125-1127

16. Barton, P., and Warren, J. S. (1993) Complement component C5 modulates the systemic tumor necrosis factor response in murine endotoxic shock. Infect. Immun. 61, 1474-1481 
17. Deitch, E. A. (1998) Animal models of sepsis and shock: a review and lessons learned. Shock 9, 1-11

18. Wichterman, K. A., Baue, A. E., and Chaudry, I. H. (1980) Sepsis and septic shock-a review of laboratory models and a proposal. J. Surg. Res. 29, 189-201

19. Huber-Lang, M. S., J. Vidya, S., McGuire, S. R., Lu, K. T., Guo, R. F., Padgaonkar, V. A., Younkin, E. M., Laudes, I. J., Riedemann, N. C., Younger, J. G., and Ward, P. A. (2001) Protective effects of anti-C5a peptide antibodies in experimental sepsis. FASEB J. 15, 568-570

20. Gerard, N. P., and Gerard, C. (1991) The chemotactic receptor for human C5a anaphylatoxin. Nature (London) 349, 614-617

21. Fureder, W., Agis, H., Willheim, M., Bankl, H. C., Maier, U., Kishi, K., Muller, M. R., Czerwenka, K., Radaszkiewicz, T., and Butterfield, J. H. (1995) Differential expression of complement receptors on human basophils and mast cells. Evidence for mast cell heterogeneity and CD88/C5aR expression on skin mast cells. J. Immunol. 155, 152-160

22. Chenoweth, D. E., and Hugli, T. E. (1978) Demonstration of specific C5a receptor on intact human polymorphonuclear leukocytes. Proc. Natl. Acad. Sci. USA 75, 3943-3947

23. Drouin, S. M., Kildsgaard, J., Haviland, J., Zabner, J., Jia, H. P., McCray, P. B., Tack, B. F., and Wetsel, R. A. (2001) Expression of the complement anaphylatoxin C3a and C5a receptors on bronchial epithelial and smooth muscle cells in models of sepsis and asthma. J. Immunol. 166, 2025-2032

24. Osaka, H., McGinty, A., Hoepken, U. E., Gerard, C., and Pasinetti, G. M. (1999) Expression of C5a receptor in mouse brain: role in signal transduction and neurodegeneration. $\mathrm{Neu}$ roscience $\mathbf{8 8 ,}, 1073-1082$

25. Zwirner, J., Fayyazi, A., and Goetze, O. (1999) Expression of the anaphylatoxin C5a receptor in non-myeloid cells. Mol. Immunol. 36, 877-884

26. Hoepken, U. E., Lu, B., Gerard, N. P., and Gerard, C. (1997) Impaired inflammatory responses in the reverse Arthus reaction through genetic deletion of the C5a receptor. J. Exp. Med. 185, $749-756$

27. Finch, A. M., Wong, A. K., Paczkowski, N. J., Wadi, S. K., Craik, D. J., Fairlie, D. P., and Taylor, S. M. (1999) Low-molecularweight peptidic and cyclic antagonists of the receptor for the complement factor C5a. J. Med. Chem. 42, 1965-1974

28. Wong, A. K., Finch, A. M., Pierens, G. K., Craik, D. J., Taylor, S. M., and Fairlie, D. P. (1998) Small molecular probe for G-protein-coupled C5a receptor conformationally constrained antagonists derived from the C-terminus of the human plasma protein C5a. J. Med. Chem. 41, 3417-3425

29. Short, A., Wong, A. K., Finch, A. M., Haaima, G., Shiels, I. A., Fairlie, D. P., and Taylor, S. M. (1999) Effects of a new C5a receptor antagonist on C5a- and endotoxin-induced neutropenia in the rat. Br. J. Pharmacol. 126, 551-554

30. Ajuebor, M. N., Das, A. M., Virag, L., Flower, R. J., Szabo, C., Perretti, M. (1999) Role of resident peritoneal macrophages and mast cells in chemokine production and neutrophil migration in acute inflammation: evidence for an inhibitory loop involving endogenous IL-10. J. Immunol. 162, 1685-1691

31. Fildes, J., Fisher, S., Sheaff, C. M., Barrett, J. A. (1998) Effects of short heat exposure on human red and white blood cells. J. Trauma 45, 479-484

32. Bennett, G. L., and Horuk, R. (1997) Iodination of chemokines for use in receptor binding analysis. Methods Enzymol. 288, $134-148$

33. Sharma, S. D., Toth, G., and Hruby, V. J. (1991) A simple general method for (radio)iodination of a phenylalanine residue in peptides: preparation of $\left[\mathrm{D}-\mathrm{Pen}^{2}, 4^{4}{ }_{-}{ }^{125} \mathrm{I}_{-} \mathrm{Phe}^{4}, \mathrm{D}-\mathrm{Pen}^{5}\right]$ enkephalin, a peptide with extraordinary selectivity for $\delta$-opioid receptors. J. Org. Chem. 56, 4981-4983

34. Short, A. J., Paczkowski, N. J., Vogen, S. M., Sanderson, S. D., and Taylor, S. M. (1999) Response-selective C5a agonists: differential effects on neutropenia and hypotension in the rat. Br. J. Pharmacol. 128, 511-514

35. Larsen, G. L., Mitchell, B. C., and Henson, P. M. (1981) The pulmonary response of C5 sufficient and deficient mice to immune complexes. Am. Rev. Respir. Dis. 123, 434-439

36. Mulligan, M. S., Schmid, E., Beck-Schimmer, B., Till, G. O., Friedl, H. P., Brauer, R. B., Hugli, T. E., Miyasaka, M., Warner, R. L., Johnson, K. J., and Ward, P. A. (1996) Requirement and role of C5a in acute lung inflammatory injury in rats. J. Clin. Invest. 98, 503-512

37. Shi, F., Ljunggren, H., and Sarvetnick, N. (2001) Innate immunity and autoimmunity: from self-protection to self-destruction. Trends Immunol. 22, 97-101

38. Prodeus, A. P., Zhou, X., Maurer, M., Galli, S. J., and Carroll, M. C. (1997) Impaired mast cell-dependent natural immunity in complement C3-deficient mice. Nature (London) 390, 172-175

39. Gommerman, J. L., Oh, D. Y., Zhou, X., Tedder, T. F., Maurer, M., Galli, S. J., and Carroll, M. C. (2000) A role for CD21/CD35 and CD19 in responses to acute septic peritonitis: a potential mechanism for mast cell activation. J. Immunol. 165, 6915-6921

40. Kildsgaard, J., Hollmann, T. J., Matthews, K. W., Bian, K, Murad, F., and Wetsel, R. A. (2000) Cutting edge: targeted disruption of the C3a receptor gene demonstrates a novel protective anti-inflammatory role for C3a in endotoxin-shock. J. Immunol. 165, 5406-5409

41. Strachnan, A. J., Woodruff, T. M., Haaima, G., Fairlie, D. P., and Taylor, S. M. (2000) A new small molecule C5a receptor antagonist inhibits the reverse-passive Arthus reaction and endotoxic shock in rats. J. Immunol. 164, 6560-6565

42. Mollison, K. W., Krause, R. A., Fey, T. A., Miller, L., Wiedeman, P. E., Kawai, M., and Lane, B. (1992) Hexapeptide analogs of C5a anaphylatoxin reveal heterogenous neutrophil agonism/ antagonism. FASEB J. 6, A2058

43. Drapeau, G., Brochu, S., Godin, D., Levesque, L., Rioux, F., and Marceau, F. (1993) Synthetic C5a receptor antagonists. Pharmacology, metabolism and in vivo cardiovascular and hematologic effects. Biochem. Pharmacol. 45, 1289-1299

44. Konteatis, Z. D., Siciliano, S. J., Van Riper, G., Molineaux, C. J., Pandya, S., Fischer, P., Rosen, H., Mumford, R. A., and Springer, M. S. (1994) Development of C5a receptor antagonists. Differential loss of functional responses. J. Immunol. 153, 4200-4205

45. Gerard, C., Bao, L., Orozco, O., Pearson, M., Kunz, D., and Gerard, N. P. (1992) Structural diversity in the extracellular faces of peptidergic G-protein-coupled receptors. Molecular cloning of the mouse C5a anaphylatoxin receptor. J. Immunol. 149, 2600-2606

46. Ward, P. A. (1996) Role of complement in lung inflammatory injury. Am. J. Pathol. 149, 1079-1086

47. Botha, A. J., Moore, F. A., Moore, E. E., Fontes, B., Banerjee, A., and Peterson, V. M. (1995) Postinjury neutrophil priming and activation states: therapeutic challenges. Shock 3, 157-166

48. Pellas, T. C., and Wennogle, L. P. (1999) C5a receptor antagonists. Curr. Pharm. Des. 5, 737-755

49. Kaneko, Y., Okada, N., Baranyi, L., Azuma, T., and Okada, H. (1995) Antagonistic peptides against human anaphylatoxin C5a. Immunology. 86, 149-154

50. Tsuji, R. F., Magae, J., Nagai, K., and Yamasaki, M. (1992) Effects of L-156,602, a C5a receptor antagonist, on mouse experimental models of inflammation. Biosci. Biotechnol. Biochem. 56, 20342036

51. Heller, T., Hennecke, M., Baumann, U., Gessner, J. E., zu Vilsendorf, A. M., Baensch, M., Boulay, F., Kola, A., Klos, A., Bautsch, W., and Kohl, J. (1999) Selection of a C5a receptor antagonist from phage libraries attenuating the inflammatory response in immune complex disease and ischemia/reperfusion injury. J. Immunol. 163, 985-994

52. Pellas, T. C., Boyar, W. van Oostrum, J., Wasvary, J., Fryer, L. R. Pastor, G., Sills, M., Braunwalder, A., Yarwood, D. R., Kramer, R., Kimble, E., Hadala, J., Haston, W., Moreira-Ludewig, R., Uziel-Fusi, S., Peters, P., Bill, K., and Wennogle, L. P. (1998) Novel C5a receptor antagonist regulate neutrophil function in vitro and in vivo. J. Immunol. 160, 5616-5621

53. Riley, R. D., Sato, H., Zhao, Z. Q., Thourani, V. H., Jordan, J. E., Fernandez, A. X., Ma, X. L., Hite, D. R., Rigel, D. F., Pellas, T. C., Peppard, J., Bill, K. A., Lappe, R. W., and Viten-Johannsen, J. (2000) Recombinant human complement C5a receptor antagonist reduces infarct size after surgical revascularization. $J$. Thorac. Cardiovasc. Surg. 120, 350-358

54. Nishiura, H., Shibuya, Y., and Yamamoto, Y. (1998) S19 ribosomal protein cross-linked dimmer causes monocyte-predominant infiltration by means of molecular mimicry to complement C5a. Lab. Invest. 78, 1615-1623

Received for publication April 26, 2002. Accepted for publication June 26, 2002. 